\title{
INVESTIGATION OF FAILURE TRADING PRACTICES IN SPORTS ACTIVITY
}

\author{
V. Dimitrov* \\ Faculty of Sport, National Sports Academy „Vassil Levski““, Sofia, Bulgaria
}

\begin{abstract}
Sporting services are increasingly important as a means of meeting the sporting needs of citizens and are an opportunity for the development of regions, including as a means of boosting employment. Due to increased competition, new unfair practices are emerging in this area. The methods used in the survey are regulatory review, case law review, and questionnaire survey. The results present the most common unfair practices and related misleading advertisements, as well as case law analysis of such cases. In conclusion, many users are misled by such practices, to put in place a reliable system for preventing sports centers, including fitness centers, from posting false reviews and recommendations on their sites.
\end{abstract}

Key words: sports, management, unfair practices, regulations, fitness

\section{INTRODUCTION}

Today's socio - economic environment requires the adoption and proposition of new approaches by sports clubs to become aware of all that they represent and do. As part of what is needed to survive and justify their existence, a new way of thinking and acting, to care for, and to the best of their members to date, it is necessary, including school and university sports clubs, to embrace the ideas of the socalled marketing orientation. In researching the development of the global sports market, Atanasova points out that the sports industry faces financial and commercial challenges (1). "When considering how many organizations can participate in the full service of sports systems, it can be visualized through the main levels of distribution and the underlying levels of sport management, including private organizations working in this direction" (2).

At the moment, the link between the environmental protection and construction standards for sports activities is particularly

\footnotetext{
*Correspondence to: Vasil Dimitrov, National Sports Academy ,,Vassil Levski“, Faculty of Sport, 1700, Sofia, Studentski grad, Email: messaiah1331@gmail.com, Mobile: +359892299705
}

relevant, and the environmental requirements for maintaining the health of athletes must be at the forefront of this type of activity (3) and this is no accident. Any deviation from these norms and requirements endangers sports activity, and in fact, general physical training proves to be extremely important for good health as well as the path to high sportsmanship (4).

Unfair practices, in turn, accompanying sports are a daily occurrence and are present in all sports and leisure activities. Starting with different types of misleading advertising and going through products with different content. The topic under discussion is regulated in Directive 2005/29 / EC of the European Parliament and of the Council of 11 May 2005 on unfair business-to-consumer commercial practices in the internal market, and the most recent significant changes in Bulgarian law have been in force since 2014 .., as last updated on 20 December 2019 (5).

Event management involves the coordination of all activities and tasks required to run an event regarding its strategy, planning, practical implementation, and control (6). 
Control is carried out by various means. Its efficiency can be greatly enhanced if it is based on the effect of the microenvironment (7).

In track and field, authors Slavchev and Gutev analyze the activities necessary for the successful running of track and field athletics of different ranks and show the need for management specialists to protect against unfair practices and activities (8).

Argirov and Draganov discuss the current problems of managing Spa and Wellness services in the Republic of Bulgaria in the conditions of economic crisis (9). It should be borne in mind that the SPA, wellness, and recreation industries are among the fastest growing sectors of modern tourism, including outdoor recreation (10).

In mass sports, and up-to-date study of the problems of sportsmen is made by Ilieva, in 2015 as she identifies the preferred ways of sports and recovery among the young (11).

The research of Tsolov's leading motives in choosing a sports venue is also relevant to the study, and it is precisely with the knowledge of the leading motives that unfair competition and practices emerge and emerge (12).

Sandanski analyzes the peculiarities of the behavior of club members, which is directly related to the means and objectives set by the organizations and their members (13).

When choosing a sport venue including fitness, it is especially important for the consumer to have clear, sufficient, non-confusing and misleading information regarding price, category, quality and location. The analysis of the survey indicates that recommendations made by other users are increasingly influencing the formation of the consumer's accommodation decision, but the recommendations may be manipulated and inspired by the merchant.

The most common consumer complaints are related to the quality of fitness services, namely: poor and unprofessional attitude of service staff, problems with heating and hygiene, non-working services (swimming pool, sauna, depreciated appliances, etc.). In addition, they receive complaints of false, incorrect or out-of-date information provided by marketers by phone or website, such as outdated photos, false positive reviews about fitness, and more. Use of a special code for viewing currently online channels which broadcasts the possibility of using a discount by entering a promotional code.

The purpose of the study is to investigate unfair practices in the field of sports, and in particular in fitness centers. By highlighting leading such violations and offering opportunities to curb unfair commercial practices in sports activities, which in turn would improve sports services and enhance their quality.

\section{METHODS}

The research methods are a normative analysis of the problem under consideration. This includes an analysis of the case law in the Republic of Bulgaria in the period 2008 2019. A review of decisions related to sports activities and unfair competition of the Consumer Protection Commission has also been made.

Over 507 cases in the past period are directly or indirectly related to sports clubs and organizations, most of which are not related to the issue under consideration, namely unfair practices. They concern violations of labor laws, faulty appliances, imposed administrative fines, and more.

There are over one hundred cases relevant to the issue under consideration. Typical cases are derived from them and are presented in groups and synthesized type. A survey was conducted in which 51 users of sports services participated in the territory of Sofia.

\section{RESULTS}

Case law analysis 2008-2019 Pursuant to Article $68 \mathrm{c}$ of $\mathrm{H}$. prohibits unfair commercial practices. Such are also misleading commercial practices within the meaning of Article 68. It is from Z. Paragraph 2 of Article 68 is from the Law on Consumer Protection. 1, the trader conceals essential information within the meaning of para. 1 or provides it in a vague, incomprehensible or ambiguous manner, or does not provide it in a timely manner, or in which the trader does not indicate his true commercial purpose if it is not understood in the context and results in, or might result in, a commercial decision being made by the average consumer, which he would not have made without the use of commercial practice. Paragraph 1 of the same article of the law 
states that the commercial practice is considered to be misleading also when from its whole factual context and taking into account all its characteristics and the circumstances and limitations of the medium used, it does not provide the essential information necessary for the average consumer, depending on the commercial decision-making situation, after acquaintance with them, which leads or may lead to the taking of a commercial decision that the average consumer would not have made without using that commercial practice.

Performing a fraudulent (misleading) commercial practice by concealing, by default, the essential information needed by the average consumer (depending on the commercial decision-making situation of the case) regarding the privileges granted to consumers by concluding a preferential fitness service contract prices in club car washes without conditions, term and specified specific objects.

What is more - the proportionality of the violation under Art. 68 is, para. 2, $\mathrm{H}$. it is necessary for the concealment of material information to result in a commercial decision being made by the average consumer, which he would not have taken without the use of process commercial practice.

To date, the term "fitness" is used in all countries in the global world, including Bulgaria, and many foods and nutritional supplements are used. In some of them, there are components that outweigh the many dangerous and many side effects molecules
The problem of fraudulent practices for fraudulent use by fitness centers is observed in more than $60 \%$ of people who have fallen into this type of deceptive fitness practice that they choose to use. This is reflected in their policy of attracting a larger pool of potential staff to earn more cash. Another reason why they take such measures is to overcome their competitors in the name of other such authorized sites that are in medicines that are under special control. Unfortunately, in Section III, Art. 79 and Art. 78 , item 2 it is entered that the competent authority for registration and enforcement of this type of food is only the director of the Bulgarian Food Safety Agency, and in para. 10 only state that it may refer to other institutions as necessary (14).

Decision No. 690 of 20.09.2016 of the Commission for Protection of Competition. In essence, the claims are directed to the thesis that when conducting online trading in sports equipment, the company engages in unfair trading practices, which consist in offering goods that are not available or at prices below the real ones, lack of warranty maintenance and no guarantee by the merchant of his goods, deliberately raising the prices of certain goods with the aim of reducing them later on to make more profits. The actions described by the petitioner, in their totality, cast doubt on the existence of an overall conduct which is contrary to good faith commercial practice within the meaning of $\S 1$, item 2 of the LPC, namely conduct contrary to the "rules governing market conduct which derive from laws and ordinary commercial relations and do not violate good morals' (15).

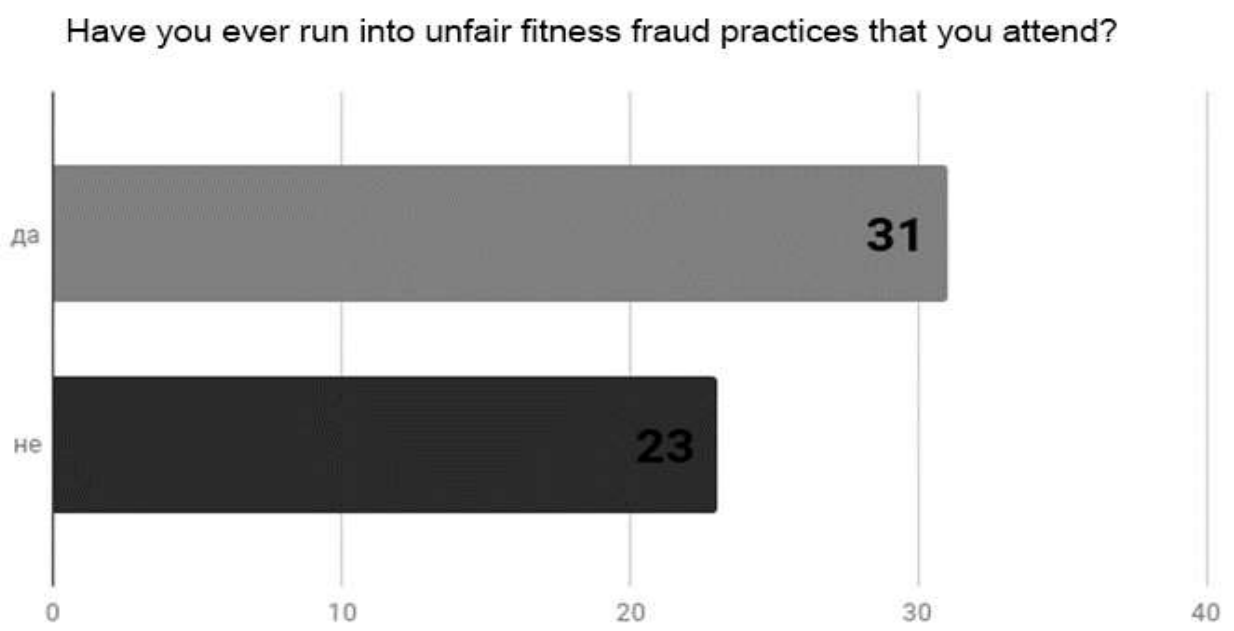

Figure 1. Unfair fitness practices. 


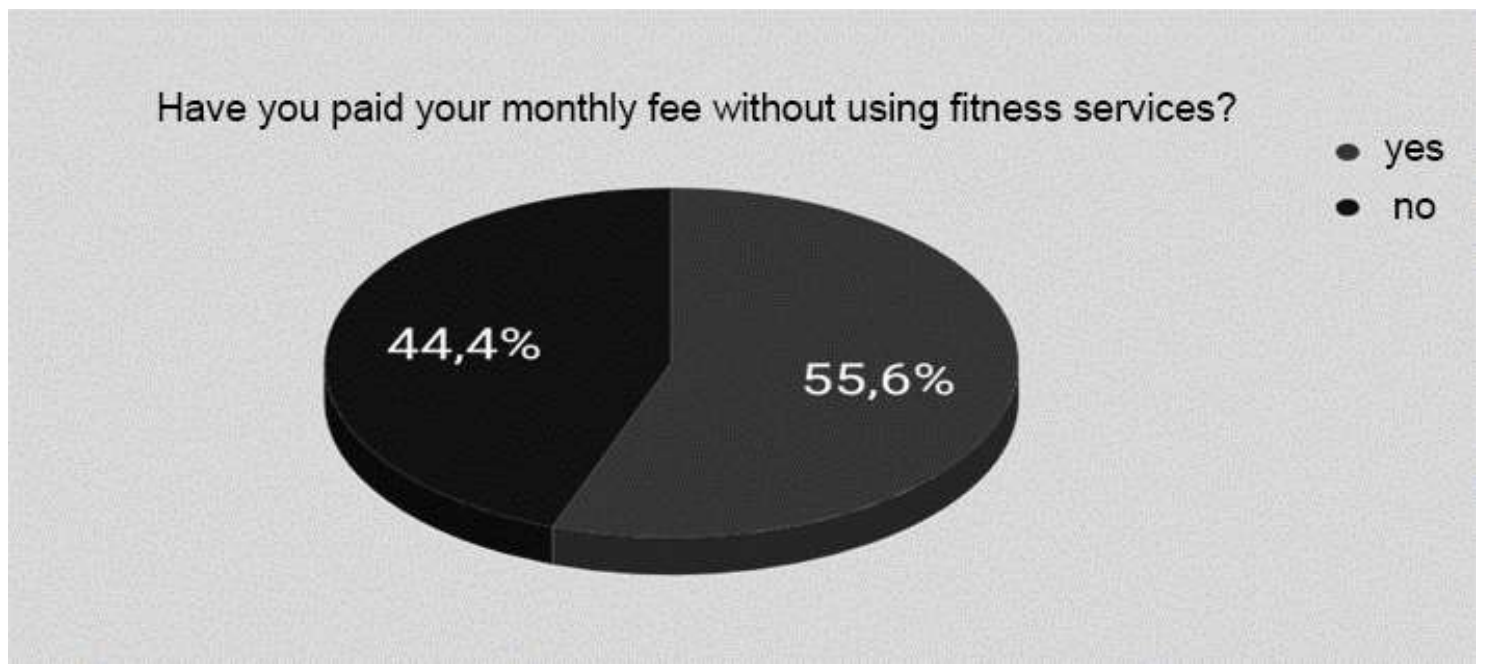

Figure 2. Using a monthly fee.

The offense committed is a continuous and persistent conduct that has been taking place for more than a year and is manifested in the supply of sporting goods online in breach of good commercial practice. As a final result, the Commission considers that the period is sufficiently long and therefore the conduct is likely to cause adverse legal effects for the applicant company and other competitors in the relevant market.

The problem of fraudulent practices for fraudulent use by fitness centers is observed in more than $60 \%$ of people who have fallen into this type of deceptive fitness practice that they choose to use. This is reflected in their policy of attracting a larger pool of potential staff to earn more cash. Another reason why they take such measures is to overcome their competitors in the name of other such authorized sites.

This case may be explained by the reasons that, in the case of a contract already signed and in the event of an emergency, an unplanned situation, the consumer may have to stop using the gym for the short term, but may not suspend payment.

\section{CONCLUSIONS}

The majority of attending sports centers is under the age of 23. Most of them are women. Logically active athletes are the largest number of visitors. The average attendance is between 2 and 3 times a week. Most have a contract for the use of sports facilities, which can be very difficult to break. The one in three victims of unfair fitness is at a fitness center. Half of the visitors were misled by one price per month card, which subsequently turned out to be different from the one initially announced. A reliable system for preventing sports centers, including fitness centers, from posting false reviews and recommendations on their sites should be put in place.

\section{REFERENCES}

1. Atanasova. N., Marketing Research in Sport, Sofia, p. 17, 2012.

2. Dimitrova, A., Volunteering in Sport - A Powerful Factor for Integration, Improving Education and Sustainable Development, Strategies for Educational and Scientific Policy, Vol. 2, 203, 2019.

3. Directive 2005/29 / EC of the European Parliament and of the Council of 11 May 2005 concerning unfair business-toconsumer commercial practices in the internal market and amending Council Directive 84/450 / EEC, Directives 97/7 / EC, 98/27 / EC and 2002/65 / EC of the European Parliament and of the Council, and Regulation (EC) No 2006/2004 of the European Parliament and of the Council ("Unfair Commercial Practices Directive"). https://eur-lex.europa.eu/legalcontent/en/TXT/?uri=CELEX:32005L0029

4. Tsvetkov, Ts., Slavchev, I., Investigation of the experience of subjects in event management, both in general and in athletics competitions. Scientific Papers of the University of Ruse, Volume 52, Series 8. 2., p. 102, 2013.

5. Doychev, B., Ecology and Sport, Avangard Prima, Sofia, p.10, 2019.

6. Tsvetkov, Ts., Slavchev, I., Investigation of the experience of subjects in event management, both in general and in athletics competitions, Scientific Papers of 
the University of Ruse, Volume 52, Series 8. 2., pp. 102, 2013

7. Dimitrova, A., Deviant Behavior in Sport: Reality and Perspectives, Monograph, NSA PRESS, Sofia, 20, 2019.

8. Slavchev, I., Gutev, G., Investigation of Functional Obligations of Organizers of Athletics of Different Ranks, Sport \& Science, Issue 4, p. 94, 2011.

9. Argirov, K., Draganov, G., Current Issues in the Management of Spa and Wellness Services in the Republic of Bulgaria in the Economic Crisis, Sport \& Science, issue 4, p.104, 2011.

10.Ivanova, V, Influence of gymnastic exercises in the water environment. Smart Innovations in the Recreational \& Wellness Industry and Niche Tourism, Vol. 1, Issue 1, p. 53-56, 2019.
11.Ilieva, D., Analysis of Sport Event Management in the Sport System for All in Bulgaria, Sport \& Science, Izv. pcs. 1, 2015.

12.Tsolov, B., Motives for Fitness Users and Factors and Factors Affecting the Fitness Center's Choice, Monograph, Sofia, p. 207, 2008.

13.Sandanski, I., Effective Marketing and Sponsorship of a School Sports Club, NSA PRESS, Sofia, 56, 2006.

14.Consumer Protection Act. Effective 10.06.2006. DV. 99 of December 9, 2005, amend. and ext. DV. Issue 100 of December 20, 2019

15.Decision No 690 of 20.09.2016 of the Competition Commission http://reg.cpc.bg/Decision.aspx?DecID=300 046648 